\title{
Factors predicting radiation pneumonitis in locally advanced non-small cell lung cancer
}

\author{
Myungsoo Kim, MD, Jihae Lee, MD, Boram Ha, MD, Rena Lee, PhD, \\ Kyung-Ja Lee, MD, Hyun Suk Suh, MD \\ Department of Radiation Oncology, Ewha Womans University School of Medicine, Seoul, Korea
}

\begin{abstract}
Purpose: Thoracic radiotherapy is a major treatment modality of stage III non-small cell lung cancer. The normal lung tissue is sensitive to radiation and radiation pneumonitis is the most important dose-limiting complication of thoracic radiation therapy. This study was performed to identify the clinical and dosimetric parameters related to the risk of radiation pneumonitis after definitive radiotherapy in stage III non-small cell cancer patients.

Materials and Methods: The medical records were reviewed for 49 patients who completed definitive radiation therapy for locally advanced non-small cell lung cancer from August 2000 to February 2010. Radiation therapy was delivered with the daily dose of 1.8 Gy to 2.0 Gy and the total radiation dose ranged from 50.0 Gy to 70.2 Gy (median, 61.2 Gy). Elective nodal irradiation was delivered at a dose of $45.0 \mathrm{~Gy}$ to $50.0 \mathrm{~Gy}$. Seven patients (14.3\%) were treated with radiation therapy alone and forty two patients (85.7\%) were treated with chemotherapy either sequentially or concurrently.

Results: Twenty-five cases (51.0\%) out of 49 cases experienced radiation pneumonitis. According to the radiation pneumonitis grade, $10(20.4 \%)$ were grade $1,9(18.4 \%)$ were grade $2,4(8.2 \%)$ were grade 3 , and $2(4.1 \%)$ were grade 4 . In the univariate analyses, no clinical factors including age, sex, performance status, smoking history, underlying lung disease, tumor location, total radiation dose and chemotherapy were associated with grade $\geq 2$ radiation pneumonitis. In the subgroup analysis of the chemotherapy group, concurrent rather than sequential chemotherapy was significantly related to grade $\geq 2$ radiation pneumonitis comparing sequential chemotherapy. In the univariate analysis with dosimetric factors, mean lung dose (MLD), $V_{20}, V_{30}, V_{40}, M L D i p s i$, $\mathrm{V}_{20} \mathrm{i} p \mathrm{ps}_{1} \mathrm{~V}_{30} \mathrm{i}$ psi, and $\mathrm{V}_{40}$ ipsi were associated with grade $\geq 2$ radiation pneumonitis. In addition, multivariate analysis showed that MLD and $V 30$ were independent predicting factors for grade $\geq 2$ radiation pneumonitis.

Conclusion: Concurrent chemotherapy, MLD and $V_{30}$ were statistically significant predictors of grade $\geq 2$ radiation pneumonitis in patients with stage III non-small cell lung cancer undergoing definitive radiotherapy. The cutoff values for MLD and $V_{30}$ were 16 Gy and $18 \%$, respectively.
\end{abstract}

Keywords: Non-small cell lung cancer, Radiation therapy, Radiation pneumonitis, Dosimetric factor

\section{Introduction}

The incidence of lung cancer in Korea is 11\%, ranking fourth, and mortality due to lung cancer continued to increase to rank first position in cancer mortality in 2008 [1]. Nonsmall cell lung cancer (NSCLC) accounts for about 75\%

Received 4 July 2011, Revised 31 August 2011, Accepted 15 September 2011.

Correspondence: Kyung-Ja Lee, MD, Department of Radiation Oncology, Ewha Womans University School of Medicine, 911 1 Mok-dong, Yangchun-gu, Seoul 158-170, Korea. Tel: +82-2-2650-5334, Fax: +82-2-2654-0363, E-mail: rokjlee@ewha.ac.kr

(c) This is an Open Access article distributed under the terms of the Creative Commons Attribution Non-Commercial License (http://creativecommons.org/ licenses/by-nc/3.0/) which permits unrestricted non-commercial use, distribution, and reproduction in any medium, provided the original work is properly cited.

www.e-roj.org 
of lung cancer and 25-40\% of cases are locally advanced disease, not amenable for curative resection at the time of diagnosis [2]. Thoracic radiotherapy was considered the standard treatment for patients with unresectable and locally advanced NSCLC. However, due to poor 5-year survival with standard radiotherapy [3], altered fraction and dose escalated radiotherapy or addition of chemotherapy to radiotherapy were attempted in order to improve the survival rate and local control rate. Recently, concurrent chemoradiotherapy has been demonstrated to increase survival to a greater degree than induction chemotherapy followed by radiotherapy. Therefore, concurrent chemoradiotherapy is currently considered as the standard of care for locally advanced stage III NSCLC $[4,5]$.

When radiotherapy is used to treat tumors within or adjacent to the thorax, the dose-limiting organs of primary concern are the lungs and the spinal cord. The lungs are sensitive to the effects of both short term and long term radiation at a lower dose than other structures in the chest, such as the esophagus, heart and spinal cord $[6,7]$. Therefore, radiation pneumonitis is the major side effect of thoracic radiation therapy that can impact the clinical course of the patients. Discontinuation of treatment or limiting the amount of radiation dose due to radiation pneumonitis leads to reduction in the therapeutic effect and decreases both the local control rate and survival rate [8].

Radiation pneumonitis usually occurs within 1-8 weeks after irradiation and its incidence ranges widely from $0 \%$ to $58 \%$. Clinical manifestation is usually mild dry cough, fever or mild dyspnea. However, severe respiratory failure can leading to death, and pulmonary fibrosis may also lead to chronic dyspnea. Radiation pneumonitis is classified in three forms; acute radiation pneumonitis within 2 months, subacute radiation pneumonitis within 2-6 months and chronic radiation pneumonitis more than 6 months after completion of radiation therapy. Mostly it appears within 2-3 months but is unlikely to occur in less than a month or after six months [9].

The factors related to the occurrence of radiation pneumonitis can be divided into clinical factors and dosimetric factors. Clinical factors associated with radiation pneumonitis are performance status [10], tumor location [11], smoking history [12] and concurrent chemotherapy $[11,13]$. Among dosimetric factors, $V_{20}$ (volume of total lung receiving $20 \mathrm{~Gy}$ or more), $V_{30}$ (volume of total lung receiving 30 Gy or more) and mean lung dose (MLD) have been used to predict the occurrence of radiation pneumonitis [14-20].

This study was performed to identify clinical and dosimetric parameters related to the risk of radiation pneumonitis after definitive radiotherapy in stage III non-small cell cancer patients, in order to reduce radiation pneumonitis in future treatments.

\section{Materials and Methods}

\section{Patients}

We retrospectively reviewed the records of patients who completed at our institution definitive radiotherapy for locally advanced NSCLC from August 2000 to February 2010. Because most of radiation pneumonitis cases occur within 6 months of radiotherapy, a minimum of 6 months follow-up was required for inclusion in this study. In all patients, history was obtained and physical examination and staging exams were performed, including chest, upper abdomen and brain computed tomography (CT). Bronchoscopy and biopsy were performed for pathological diagnosis. Clinical evaluation of staging was based on the 2002 American Joint Committee on Cancer (AJCC) staging classification and the performance status was assessed according to Eastern Cooperative Oncology Group (ECOG) performance scale.

\section{Radiotherapy}

All patients underwent three-dimensional treatment planning and radiotherapy was delivered using a linear accelerator (Primus, Siemens, German) with 6 MV or 10 MV photon beam, with a daily dose 1.8 to $2.0 \mathrm{~Gy}$. The total radiation dose ranged from 50.0 Gy to 70.2 Gy (median, 61.2 Gy). Elective nodal irradiation was delivered at a total dose of $45.0 \mathrm{~Gy}$ to $50.0 \mathrm{~Gy}$.

Patients were placed in the treatment position (generally supine, with arms above the head) and immobilized in a custom-made device to improve the setup reproducibility during planning and treatment. Planning CT scan was performed in the immobilization device, with the patients breathing freely, and included the entire lung volume. A scan thickness of $3 \mathrm{~mm}$ was used. Gross tumor volume (GTV) was defined as all gross disease defined by the planning CT and clinical information (GTV primary), as well as the enlarged regional lymph nodes over $1.0 \mathrm{~cm}$ in the short-axis (GTV node). The clinical target volume (CTV) included the GTV with $2.0-2.5 \mathrm{~cm}$ margin in all directions, plus the ipsilateral hilum and the entire mediastinum and supraclavicular area, for patients with apical tumors and with enlargement of the supraclavicular lymph nodes. The planning target volume (PTV) was defined as CTV plus $0.5-1.0 \mathrm{~cm}$ margin in all directions. 
The prescribed dose was mostly 61.2 Gy in 34 fractions. The heterogeneity correction was used and the dose was prescribed at the isocenter. PTV was encouraged to cover $90 \%$ of isodose surface. Normal tissue constraints were prioritized for treatment planning, in the following order: the maximum spinal cord dose did not exceed $40 \mathrm{~Gy}$ and the volume of total lung receiving 20 Gy or more $\left(V_{20}\right)$ was below $35 \%$.

\section{Dosimetric factors}

Radiation doses were extracted only from the cumulative dose-volume histograms. $V n$ was defined as the volume of total lung receiving at least $n$ Gy of radiation. Data points extracted from the dose-volume histograms were obtained, including $V_{10}, V_{20}, V_{30}, V_{40}$, and MLD. The same parameters were evaluated ipsilaterally and were recorded as $V_{20}$ ipsi, $V_{30}$ ipsi, $V_{40}$ ipsi, and MLDipsi, respectively. Total lung was defined as (right lung + left lung) - GTV. Accordingly, the ipsilateral lung was defined as right lung/left lung - PTV.

\section{Chemotherapy}

Forty-two patients received chemotherapy, i.e., 14 patients concurrently, and 28 sequentially. Chemotherapy regimens were paclitaxel + carboplatin in 20 patients, gemcitabine + cisplatin in 9 patients, gemcitabine + carboplatin in 5 patients, paclitaxel + cispltin in four patients, docetaxel + cisplatin in 2 patients, docetaxel + carboplatin in one patient and vinorebine + cisplatin in one patient.

Table 1. Common Toxicity Criteria for Adverse Events v4.0

\begin{tabular}{ccc}
\hline Adverse event & Grade & Description \\
\hline Pneumonitis & 1 & $\begin{array}{c}\text { Asymptomatic, clinical or } \\
\text { diagnostic observations only, } \\
\text { intervention not indicated } \\
\text { Symptomatic, medical } \\
\text { intervention indicated, limiting } \\
\text { instrumental ADL } \\
\text { Severe symptoms, limiting self } \\
\text { care ADL, oxygen indicated } \\
\text { Life-threatening respiratory } \\
\text { compromise; urgent } \\
\text { intervention indicated (e.g., } \\
\text { tracheotomy or intubation) } \\
\text { Death }\end{array}$ \\
& \\
&
\end{tabular}

$A D L$, activities of daily life.

Available from: http://ctep.cancer.gov/reporting/ctc.html.

\section{Follow-up and evaluation of radiation pneumonitis}

Patients were evaluated for follow-up with weekly chest $X$-rays and when clinically indicated during radiation treatment. The first follow-up visit was one month after completion of treatment, every 3 months for the first 2 years and every 6 months thereafter. At the time of the regular follow-ups, routine laboratory studies, chest $X$-ray and chest CT scans were taken. Radiation pneumonitis was graded according to the National Cancer Institute of the Common Toxicity Criteria for Adverse Events version 4.0 (CTCAE) (Table 1).

\section{Statistical analysis}

Univariate logistic regression analysis was used to test the association between Vn/MLD and radiation pneumonitis. For the multivariate analysis, forward stepwise logistic regression analysis was adopted. Patients were grouped based on the development of grade 0 to 1 vs. grade 2 to 5 pneumonitis. Receiver-operating characteristic (ROC) curves were generated to define the cutoff value. Statistical tests were performed using SPSS ver. 16.0 (SPSS Inc., Chicago, IL, USA) and statistical significance was defined as a $p$-value $\leq 0.05$.

\section{Results}

\section{Patients' characteristics}

From August 2000 to February 2010, 79 patients with biopsy proven NSCLC stage III underwent definitive radiotherapy at our institution. Of these, we retrospectively analysed data for 49 patients who completed radiotherapy and had a minimum of 6 months follow-up duration. The characteristics of patients are summarized in Table 2. There was a male predominance (44 male [89.8\%] vs. 5 female [10.2\%]). The patients' age ranged from 43 to 81 years (median, 63 years) and the majority of patients were in their 50s or 60s. Pathologically, 31 patients (63.3\%) had squamous cell carcinoma, 17 patients (34.7\%) had adenocarcinoma and 1 patient (2.0\%) had large cell carcinoma. 40 patients (81.6\%) had past smoking history. 10 patients (20.4\%) had underlying lung disease, 5 (10.2\%) were pulmonary tuberculosis, 3 (6.1\%) were chronic obstructive pulmonary disease (COPD) and 2 patients (4.1\%) had both diseases. ECOG performance status was 1 in 42 patients (85.7\%), 2 in 6 patietns (12.2\%) and 0 in 1 patient (2.1\%). Seven patients (14.3\%) were treated with radiation therapy alone and forty two patients (85.7\%) were treated with chemotherapy either sequentially or concurrently. Of 
Table 2. Patient characteristics $(n=49)$

\begin{tabular}{|c|c|c|}
\hline Characteristics & $\begin{array}{c}\text { No. of } \\
\text { patients }\end{array}$ & $\%$ \\
\hline \multicolumn{3}{|l|}{ Age (yr) } \\
\hline Median (range) & $63(43-81)$ & \\
\hline \multicolumn{3}{|l|}{ Sex } \\
\hline Male & 44 & 89.8 \\
\hline Female & 5 & 10.2 \\
\hline \multicolumn{3}{|l|}{ ECOG } \\
\hline $0-1$ & 43 & 87.8 \\
\hline $2-3$ & 6 & 12.2 \\
\hline \multicolumn{3}{|l|}{ Smoking history } \\
\hline No & 9 & 18.4 \\
\hline Yes & 40 & 81.6 \\
\hline \multicolumn{3}{|l|}{ Underlying lung disease } \\
\hline No & 39 & 79.6 \\
\hline Yes & 10 & 20.4 \\
\hline \multicolumn{3}{|l|}{ Histology } \\
\hline Squamous cell carcinoma & 31 & 63.3 \\
\hline Adenocarcinoma & 17 & 34.7 \\
\hline Large cell carcinoma & 1 & 2.0 \\
\hline \multicolumn{3}{|l|}{ Clinical stage } \\
\hline$\| \mathrm{A}$ & 19 & 38.8 \\
\hline IIIB & 30 & 61.2 \\
\hline \multicolumn{3}{|l|}{ Tumor location } \\
\hline Right & 28 & 57.1 \\
\hline Left & 21 & 42.9 \\
\hline Upper & 32 & 65.3 \\
\hline Middle \&t central & 3 & 6.1 \\
\hline Lower lob. & 14 & 28.6 \\
\hline \multicolumn{3}{|l|}{ RT dose (Gy) } \\
\hline Median (range) & $61.2(50.0-70.2)$ & \\
\hline$<60$ & 13 & 26.5 \\
\hline$\geq 60$ & 36 & 73.5 \\
\hline \multicolumn{3}{|l|}{ Chemotherapy } \\
\hline None & 7 & 14.3 \\
\hline Sequential & 28 & 57.1 \\
\hline Concurrent & 14 & 28.6 \\
\hline
\end{tabular}

ECOG, Eastern Cooperative Oncology Group; RT, radiation therapy.

forty two patients who received chemotherapy, 28 patients (57.1\%) received sequential chemoradiotherapy and 14 (28.6\%) received concurrent chemoradiotherapy; 11 of this 14 patients also received induction chemotherapy. The prescribed dose for primary lesions ranged from 50 Gy to 70.2 Gy (median, 61.2 Gy). 36 patients (73.5\%) received 60.0 Gy or more, whereas 13 patients (26.5\%) received less than 60 Gy. The mean duration of radiotherapy was 50.9 days (range, 37 to 73 days).
Table 3. Pulmonary toxicity according to Common Toxicity Criteria for Adverse Events v4.0 grading scale

\begin{tabular}{cc}
\hline Grade & No. of patients $(\%)$ \\
\hline 0 & $24(49.0)$ \\
1 & $10(20.4)$ \\
2 & $9(18.4)$ \\
3 & $4(8.2)$ \\
4 & $2(4.1)$ \\
5 & $0(0)$ \\
\hline
\end{tabular}

\section{Clinical manifestations of radiation pneumonitis}

Of 49 investigated patients, 25 (51.0\%) developed radiation pneumonitis: $10(20.4 \%)$ grade 1, 9 (18.4\%) grade 2, 4 (8.2\%) grade 3 , and $2(4.1 \%)$ grade 4 , according to the CTCAE ver. 4.0 classification. There was no death related to radiation pneumonitis (Table 3). The median time to diagnosis of pneumonitis was 3.0 months from initiation of radiotherapy and 1.3 months from completion of radiotherapy. Two patients developed radiation peumonitis during radiotherapy. According to the onset of radiation pneumonitis, acute radiation pneumonitis (occuring within 2 months after radiotherapy), subacute radiation pneumonitis (occuring 2 to 6 months after radiotherapy), and chronic radiation pneumonitis cases (occuring 6 months after radiotherapy) were 20 (80.0\%), 5 $(20.0 \%)$, and $0(0 \%)$, respectively.

Treatment using corticosteroid was performed in 14 of 15 patients (93.3\%) with grade $\geq 2$ radiation peumonitis.

\section{Analysis of factors predicting radiation pneumonitis}

In the univariate analysis, no clinical factors (including age, sex, performance status, smoking history, underlying lung disease, tumor location, total radiation dose and chemotherapy) were associated with grade $\geq 2$ radiation pneumonitis. In the subgroup analysis of chemotherapy group, concurrent rather than sequential chemotherapy was significantly related with grade $\geq 2$ radiation pneumonitis $(p=0.006)$ (Table 4$)$.

Table 5 shows the mean MLD, $V_{10}, V_{20}, V_{30}, V_{40}$, MLDipsi (ipsilateral MLD), $V_{10} i p s i, V_{20} i p s i, V_{30} i p s i$ and $V_{40} i p s i$ for all patients and in patients with grade $0-1$ and grade $\geq 2$ radiation pneumonitis. In the univariate analysis with dosimetric factors, $\operatorname{MLD}(p=0.003), V_{20}(p=0.017), V_{30}(p=0.001), V_{40}(p=0.004)$, MLDipsi $(p=0.003), V_{20} i p s i(p=0.008), V_{30} i p s i(p=0.004)$, and $V_{40} i p s i(p=0.008)$ were all associated with highergrade radiation pneumonitis. In contrast, multivariate analysis showed that only MLD (odds ratio [OR], 2.148; 95\% confidence interval $[\mathrm{Cl}]$, 1.029 to $4.481 ; p=0.042)$ and $\mathrm{V}_{30}(\mathrm{OR}, 2.510 ; 95 \%$ 
$\mathrm{Cl}, 1.092$ to $5.771 ; p=0.030$ ) were independent predicting factors for grade $\geq 2$ radiation pneumonitis (Table 6 ). The mean value of MLD was 16.3 Gy for all patients, i.e., 15.0 Gy for patients who developed grade 0 to 1 radiation pneumonitis

Table 4. Patient and tumor characteristics according to radiation pneumonitis grade

\begin{tabular}{|c|c|c|c|}
\hline Variable & $\begin{array}{l}\text { RP grade } 0-1 \\
\quad(n=34)\end{array}$ & $\begin{array}{c}\text { RP grade } \geq 2 \\
(n=15)\end{array}$ & $p$-value \\
\hline Age (yr) & $62.8(S D, 8.6)$ & $62.6(S D, 8.3)$ & 0.923 \\
\hline \multicolumn{4}{|l|}{ Sex } \\
\hline \multicolumn{4}{|l|}{ ECOG } \\
\hline $0-1 / 2-3$ & $31 / 3$ & $12 / 3$ & 0.283 \\
\hline \multicolumn{4}{|l|}{ Smoking } \\
\hline No/yes & $5 / 29$ & $4 / 11$ & 0.325 \\
\hline \multicolumn{4}{|l|}{ Lung disease } \\
\hline No/yes & $26 / 7$ & $13 / 3$ & 0.962 \\
\hline \multicolumn{4}{|l|}{ Tumor location } \\
\hline Right/left & $22 / 12$ & $6 / 9$ & \\
\hline $\begin{array}{l}\text { Upper/middle } \\
\text { \& lower }\end{array}$ & $24 / 10$ & $8 / 7$ & 0.246 \\
\hline \multicolumn{4}{|l|}{ RT dose (Gy) } \\
\hline$<60 / \geq 60$ & $9 / 25$ & $4 / 11$ & 0.989 \\
\hline \multicolumn{4}{|l|}{ Chemotherapy } \\
\hline No/yes & $4 / 30$ & $3 / 12$ & 0.452 \\
\hline \multicolumn{4}{|l|}{$\begin{array}{l}\text { Concurrent } \\
\text { chemotherapy }\end{array}$} \\
\hline No/yes & $28 / 6$ & $7 / 8$ & 0.006 \\
\hline
\end{tabular}

$\mathrm{RP}$, radiation pneumontis; SD, standard deviation; ECOG, Eastern Cooperative Oncology Group. and 19.1 Gy for patients who developed grade $\geq 2$ radiation pneumonitis. The mean value of $V_{30}$ was $19.2 \%$ for all patients, i.e., $17.4 \%$ for patients who developed grade 0 to 1 radiation pneumonitis and $23.1 \%$ for patientswho developed grade $\geq 2$ radiation pneumonitis.

The cutoff values of MLD and $V_{30}$, as calculated by the ROC curves, were 16 Gy and 18\%, respectively. The incidence of grade $\geq 2$ radiation pneumonitis was $8 \%$ if MLD was $\leq 16$ Gy and $54.2 \%$ if MLD was $>16$ Gy $(p=0.001)$. Similarly, the incidence of grade $\geq 2$ radiation pneumonitis was $8.3 \%$ if $V_{30}$ was $\leq 18 \%$ and $52 \%$ if $\bigvee_{30}$ was $>18 \%(p=0.001)$ (Table 7).

\section{Discussion and Conclusion}

Radiation pneumonitis is one of the most significant

Table 6. Multivariate analysis of dosimetric factors for predicting development of grade $\geq 2$ radiation pneumonits

\begin{tabular}{lccc}
\hline \multicolumn{1}{c}{ Variable } & Odds ratio & $95 \% \mathrm{Cl}$ & $\mathrm{p}$-value \\
\hline MLD (Gy) & 2.148 & $1.029-4.481$ & 0.042 \\
$\mathrm{~V}_{20}(\%)$ & 0.679 & $0.418-1.104$ & 0.119 \\
$\mathrm{~V}_{30}(\%)$ & 2.510 & $1.092-5.7701$ & 0.030 \\
$\mathrm{~V}_{40}(\%)$ & 0.483 & $0.232-1.0075$ & 0.052 \\
MLDipsi (Gy) & 0.879 & $0.662-1.168$ & 0.375 \\
$\mathrm{~V}_{20}$ ipsi (\%) & 0.988 & $0.792-1.258$ & 0.989 \\
$\mathrm{~V}_{30}$ ipsi (\%) & 0.869 & $0.5412-1.397$ & 0.562 \\
$\mathrm{~V}_{40}$ ipsi (\%) & 1.311 & $0.916-1.877$ & 0.139 \\
\hline
\end{tabular}

$\mathrm{Cl}$, confidence interval; $\mathrm{MLD}$, mean lung dose; $\mathrm{V}_{20}$, volume of total lung receiving 20 Gy or more; MLDipsi, ipsilateral mean lung dose; $V_{20}$ ipsi, volume of ipsilateral lung receiving $20 \mathrm{~Gy}$ or more.

Table 5. Patient characteristics

\begin{tabular}{|c|c|c|c|c|c|}
\hline \multirow[b]{2}{*}{ Variable } & \multicolumn{3}{|c|}{ Value } & \multirow[b]{2}{*}{$p$-value } & \multirow{2}{*}{$\begin{array}{l}\text { ROC } \\
\text { AUC }\end{array}$} \\
\hline & $\begin{array}{c}\text { All patients } \\
(n=49)\end{array}$ & $\begin{array}{l}\text { RP grade } 0-1 \\
\quad(n=34)\end{array}$ & $\begin{array}{c}\text { RP grade } \geq 2 \\
(n=15)\end{array}$ & & \\
\hline MLD (Gy) & $16.3(3.9)$ & $15.0(3.4)$ & $19.1(3.5)$ & 0.003 & 0.792 \\
\hline$V_{10}(\%)$ & $46.2(10.7)$ & $44.6(11.1)$ & 49.8 (8.8) & 0.121 & 0.651 \\
\hline$V_{20}(\%)$ & $29.0(6.3)$ & $27.5(6.1)$ & $32.5(5.4)$ & 0.017 & 0.753 \\
\hline$V_{30}(\%)$ & $19.2(5.1)$ & $17.4(4.1)$ & $23.1(5.0)$ & 0.001 & 0.814 \\
\hline$V_{40}(\%)$ & $12.5(4.7)$ & $11.1(3.9)$ & $15.7(5.0)$ & 0.004 & 0.765 \\
\hline MLDipsi (Gy) & $23.2(6.3)$ & $21.2(5.1)$ & $27.7(6.7)$ & 0.003 & 0.788 \\
\hline$V_{10}$ ipsi (\%) & $59.6(14.0)$ & $58.2(13.5)$ & $62.9(15.0)$ & 0.276 & 0.624 \\
\hline V & $45.2(11.5)$ & $42.1(10.1)$ & $52.3(11.7)$ & 0.008 & 0.771 \\
\hline V $_{30}$ ipsi (\%) & 35.7 (10.9) & $32.3(8.4)$ & 43.4 (12.3) & 0.004 & 0.772 \\
\hline$V_{40}$ ipsi (\%) & $25.5(11.1)$ & $22.3(8.4)$ & 32.9 (13.1) & 0.008 & 0.764 \\
\hline
\end{tabular}

Values are presented as mean (standard deviation).

$R P$, radiation pneumonitis; $R O C$, receiver operating characteristic; $A U C$, area under ROC curve; MLD, mean lung dose; $V_{10}$, volume of total lung receiving $10 \mathrm{~Gy}$ or more; MLDipsi, ipsilateral mean lung dose; $V_{10}$ ipsi, volume of ipsilateral lung receiving $10 \mathrm{~Gy}$ or more. 
Table 7. Risk groups of patients according to dosimetric constraints

\begin{tabular}{cccc}
\hline Variable & Cut off & $\begin{array}{c}\text { Acutual incidence } \\
\text { of lung toxicity of } \\
\text { grade } \geq 2 \text { RP }(\%)\end{array}$ & $\begin{array}{c}\text { p-value } \\
\text { (fisher exact test) }\end{array}$ \\
\hline MLD (Gy) & $\leq 16$ & 8 & 0.001 \\
& $>16$ & 54.2 & \\
$\mathrm{~V}_{30}(\%)$ & $\leq 18$ & 8.3 & 0.001 \\
& $>18$ & 52 & \\
\hline
\end{tabular}

$R P$, radiation pneumonitis; $M L D$, mean lung dose; $V_{30}$, volume of total lung receiving $30 \mathrm{~Gy}$ or more.

complications associated with thoracic radiotherapy. It affects the respiratory function and quality of life and may also lead to death in severe cases. The incidence of radiation pneumonits varies widely between reports, ranging from 0 to $58 \%$. Differences in radiation technique, awareness, method of reporting and evaluation of the symptoms themselves may account for this variability [9,21-23]. In this study, in 49 patients receiving thoracic radiation therapy and chemotherapy, the incidence of radiation pneumonitis was $30.6 \%$, which was higher than 10-20\% reported in the study of Roach et al. [24]. Tsoutsou and Koukourakis [21] reported that both the rate and severity of symptoms increased when large lung volumes were included or high doses (>50 Gy) were applied, especially when combined with chemotherapy. They showed that $50-90 \%$ of patients undergoing irradiation to the lung developed radiographic and pulmonary function test abnormalities within a time frame of 12 weeks after radiation therapy (RT).

A review of published studies showed that the ideal dosevolume histogram metric for predicting the risk of radiation pneumonitis has not yet been identified. In the study of Graham et al. [14], half of the patients were treated with radiotherapy and half with radiochemotherapy. The incidence of pneumonitis was up to $20 \%$, but only $7 \%$ if the $V_{20}$ value was 31\% or lower. Similarly, in the trial of Tsujino et al. [16], all patients were treated by adding chemotherapy to radiotherapy in a concomitant set, and the incidence of pneumonitis increased up to $51 \%$ with the standard dosimetric constraints. Only with very low values of $V_{20}$ did the pneumonitis risk become acceptable $\left(8.7 \%\right.$ for $\left.V_{20} \leq 20 \%\right)$. This means that the use of constraints lower than $V_{20}$ is paramount to avoid pulmonary toxicity. In our study, the mean value of $\mathrm{V}_{20}$ was $29.0 \%$ for all patients, i.e., $27.5 \%$ for patients who developed grade 0 to 1 radiation pneumonitis, and 32.5\% for patients who developed grade $\geq 2$ radiation pneumonitis. The difference was statistically significant in univariate, but not multivariate analysis.

Wang et al. [17] reported that the incidence of radiation pneumonitis was $10 \%$ if $\mathrm{V}_{30}<22 \%$ and increased to $36 \%$ if $V_{30} \geq 22 \%$. In the experience of Hernando et al. [15], the global rate of pulmonary toxicity was 19\%, but it was only $6 \%$ when $V_{30}$ was $18 \%$ or lower; thus, the authors suggested the cutoff value of $\mathrm{V}_{30}$ as $18 \%$. Fay et al. [18] also reported that the incidence of radiation pneumonitis was $15 \%$ if $V_{30}<22 \%$ and $37 \%$ if $\mathrm{V}_{30} \geq 22 \%$. In our study, $\mathrm{V}_{30}$ was a statistically significant predictor of grade $\geq 2$ radiation pneumonitis and the mean value in all patients was $19.2 \%$, i.e., $17.4 \%$ for grade $0-1$ pneumonitis, and $23.1 \%$ for grade $\geq 2$ radiation pneumonitis. In our study, the cutoff value of $\mathrm{V}_{30}$ was $18 \%$, similar to the results of Hernando et al. [15].

Graham et al. [14] reported that MLD was a statistically significant predictor of radiation pneumonitis. The incidence of grade $\geq 2$ radiation pneumonitis was $8 \%$ if $M L D<20$ Gy and $24 \%$ if MLD $\geq 20$ Gy. Wang et al. [17] also reported that the incidence of radiation pneumonitis was 13\% if MLD $\leq 16 \mathrm{~Gy}$ and $36 \%$ if MLD > $16 \mathrm{~Gy}$. In our study MLD was also a statistically significant predictor of grade $\geq 2$ radiation pneumonitis and its mean value in all patients was $16.3 \mathrm{~Gy}$, i.e., $15.0 \mathrm{~Gy}$ for grade $0-1$ and $19.2 \mathrm{~Gy}$ for grade $\geq 2$ radiation pneumonitis. The cutoff value of MLD was 18\% in our study, similar to the results of Wang et al. [17] (Table 8).

Pulmonary function results from the function of the right and left lung; therefore, in investigations related to toxicity, the lungs were usually considered as a unique organ unit. To date and to the best of our knowledge, only few authors have examined the effect of the radiation dose applied to the ipsilateral and contralateral lungs separately, with respect to tumor location. In the study of Oetzel et al. [25] the lungs were analyzed as separate organs. The toxicity rate was $0 \%$ if MLDipsi was 15 Gy or lower, 13\% if MLDipsi was 17.5 to 20 Gy, 21\% if MLDipsi was 22.5 to $25 \mathrm{~Gy}$ and $43 \%$ if MLDipsi was $27.5 \mathrm{~Gy}$ or higher. Correlation between the irradiation dose to the ipsilateral lung and pneumonitis has been reported in two studies, i.e., Seppenwoolde et al. [26] and Yorke et al. [27]. In the latter study, the strongest correlation with pneumonitis was found for $V_{5}$ through $V_{30}$ in the ipsilateral lung, but the authors did not suggest a constraint. In the study of Ramella et al. [28], $V_{20}$ ipsi was proven as an effective classification criterion, substantially dividing the patients into two groups. The $\mathrm{V}_{20}$ ipsi threshold value was $52 \%$, with toxicity rate ranging 
Table 8. Predictive dosimetric factors of radiation pneumonitis

\begin{tabular}{|c|c|c|c|c|c|}
\hline Author & Grade & MLD (Gy) & $\%$ & $V_{\text {dose }}(\%)$ & $\%$ \\
\hline \multirow[t]{3}{*}{ Graham et al. [14] } & $\geq 2^{\text {a) }}$ & $<20$ & 8 & $V_{20} 31$ & 7 \\
\hline & & $>20$ & 24 & $V_{20} 32-40$ & 13 \\
\hline & & & & $V_{20}>40$ & 36 \\
\hline \multirow[t]{3}{*}{ Hernando et al. [15] } & $\geq 2^{b)}$ & $11-20$ & 16 & $V_{30} \leq 18$ & 6 \\
\hline & & $21-30$ & 27 & $V_{30}>18$ & 24 \\
\hline & & $>30$ & 44 & & \\
\hline \multirow[t]{4}{*}{ Tsujino et al. [16] } & $\geq 2^{c)}$ & & & $V_{20} \leq 20$ & 8.7 \\
\hline & & & & $V_{20} 21-25$ & 18.3 \\
\hline & & & & $V_{20} 26-30$ & 51 \\
\hline & & & & $V_{20} \geq 31$ & 85 \\
\hline \multirow[t]{2}{*}{ Fay et al. [18] } & $A I^{c}$ & & & $V_{30}<22$ & 15 \\
\hline & & & & $V_{20} \geq 22$ & 37 \\
\hline \multirow[t]{2}{*}{ Wang et al. [17] } & $\geq 3^{\mathrm{d})}$ & $\leq 16$ & 13 & $V_{30} \leq 22$ & 10 \\
\hline & & $>16$ & 36 & $V_{30}>22$ & 36 \\
\hline \multirow[t]{2}{*}{ Current study } & $\geq 2^{\mathrm{e})}$ & $\leq 16$ & 8 & $V_{30} \leq 18$ & 8.3 \\
\hline & & $>16$ & 54.2 & $V_{30}>18$ & 52 \\
\hline
\end{tabular}

$M L D$, mean lung dose; $V_{\text {doser }}$ volume of total lung receiving (dose) Gy or more.

${ }^{a)} \mathrm{RTOG}$ score for acute toxicity. ${ }^{b)}$ Institutional criteria (similar to Common Toxicity Criteria [CTC]). ${ }^{\mathrm{c}} \mathrm{CTC}$, ver. $2.0 .{ }^{d)} \mathrm{CTC}$, ver. $3.0 .{ }^{\text {e) }} \mathrm{CTC}$, ver. 4.0.

from 9\% (if $V_{20}$ ipsi was $\leq 52 \%$ ) to $46 \%$ (if $V_{20}$ ipsi was $>52 \%$ ) ( $p$ $<0.05$ ). $V_{20}$ ipsi and $V_{30}$ ipsi were important if the $V_{20}$ to the total lung, $V_{30}$ to the total lung and MLD have not exceeded the constraints of $31 \%, 18 \%$, and $20 \mathrm{~Gy}$, respectively. In this study, MLDipsi, $V_{10}$ ipsi, $V_{20}$ ipsi, $V_{30}$ ipsi and $V_{40}$ ipsi were calculated and all of them, except $V_{10}$ ipsi, were significantly associated with radiation pneumonitis in the univariate, but not multivariate analysis.

Several clinical factors, such as old age ( $\geq 60$ years), female, underlying lung disease and pulmonary function, have been previously reported as independent predictors for radiation pneumonitis. Treatment related factors included the total radiation dose, treatment field, chemotherapy regimen and concurrent chemoradiotherapy $[10,11,13,15,22,29]$ (Table 9). In our univariate analysis, no clinical factors (including age, sex, performance status, smoking history, underlying lung disease, tumor location, total radiation dose and chemotherapy) were associated with grade $\geq 2$ radiation pneumonitis. However, in the subgroup analysis of chemotherapy group, concurrent rather than sequential chemotherapy was significantly related to grade $\geq 2$ radiation pneumonitis $(p=0.006)$ (Table 4$)$.

Long-standing efforts have been made to develop pharmacologic agents that protect normal tissues from the effects of radiation. One very promising radioprotector emerging from these efforts was amifostine, an organic thiophosphate. The active metabolite is a free thiol thought to provide an alternative target for reactive species from alkylating agents that would otherwise target DNA. The free thiol is also believed to scavenge the free radicals released during the interaction between ionizing radiation and water [30,31]. In the study of Komaki et al. [31], 62 patients received hyperfractionated thoracic radiotherapy with chemotherapy, and there was a statistically significant reduction in the incidence of severe (grade 3) pneumonitis in the patients who received amifostine, compared to those who did not. (16\% vs. $0 \%, p=0.020)$.

According to Mehta's hypothesis [32], the safest approach is likely to be limiting both the amount of radiation and the volume of normal lung that is irradiated. Improvement of local tumor control and consecutively overall survival by dose escalation has become an important issue. Inverse treatment planning and intensity-modulated radiation therapy (IMRT) enables dose escalation at specific tumor sites and provides a potential for sparing organs in the vicinity, especially the concave targets, to an extent that was not possible before. Volume restriction seems to be the most important issue in dose escalation. Irradiation of normal tissue can be reduced by omission of clinically uninvolved lymph-node areas, maximal set-up accuracy and decreased tumor mobility through respiratory gating and image guidance. In patients with inoperable stage III NSCLC treated with concurrent chemoradiotherapy, Yuan et al. [33] reported that the rate of 
Table 9. Clinical prognostic factors related to radiation pneumonitis

\begin{tabular}{|c|c|c|c|}
\hline \multirow[t]{2}{*}{ Author } & \multirow[t]{2}{*}{ Grade } & \multicolumn{2}{|c|}{$\begin{array}{c}\text { Effects of the clinical } \\
\text { parameters }\end{array}$} \\
\hline & & Increased risk & No effect \\
\hline Byhardt et al. [13] & $\geq 3^{\text {a) }}$ & CCT & NR \\
\hline Yamada et al. [11] & $\geq 2^{\text {a) }}$ & $\begin{array}{l}\text { Tumor location, } \\
\text { CCT }\end{array}$ & $\begin{array}{l}\text { Pulmonary } \\
\text { fibrosis }\end{array}$ \\
\hline Robnett et al. [10] & $\geq 3^{\text {a) }}$ & $\begin{array}{l}\text { Female sex, KPS } \\
\text { low }(\text { ECOG } \leq 1) \\
\text { FEV1 low }(\leq 2.01)\end{array}$ & $\begin{array}{l}\mathrm{CT} \text {, timing of } \mathrm{CT}_{1} \\
\text { tumor location }\end{array}$ \\
\hline Inoue et al. [22] & $\geq 3^{\text {a) }}$ & $\begin{array}{l}\mathrm{paO}_{2} \text { low }(<80 \\
\mathrm{mmHg}) \text {, } \\
\text { increment CRP } \\
(>1 \mathrm{ng} / \mathrm{mL})\end{array}$ & $\begin{array}{l}\text { CT, DLCO, timing } \\
\text { CT }\end{array}$ \\
\hline $\begin{array}{l}\text { Hernando } \\
\text { et al. [15] }\end{array}$ & $A I^{b)}$ & $\begin{array}{l}\text { Smoking, weight } \\
\text { loss }\end{array}$ & $\begin{array}{l}\text { Tumor location, } \\
\text { FEV }_{1}, \mathrm{CT}\end{array}$ \\
\hline Rancati et al. [29] & $\geq 2^{c)}$ & $\mathrm{CT}, \mathrm{COPD}$ & $\begin{array}{l}\text { Gender, previous } \\
\text { surgery }\end{array}$ \\
\hline Current study & $\geq 2^{\mathrm{d})}$ & СCT & $\begin{array}{l}\text { Age, gender, } \\
\text { ECOG, smoking, } \\
\text { tumor location. } \\
\text { previous } \\
\text { pulmonary } \\
\text { disease, RT dose }\end{array}$ \\
\hline
\end{tabular}

CCT, concurrent chemotherapy; NR, not reported; KPS, Karnofsky performance status; ECOG, Eastern Cooperative Oncology Group; $\mathrm{CT}$, chemotherapy; FEV1, forced expiratory volume in $1 \mathrm{sec} ; \mathrm{paO}_{2}$, arterial oxygen pressure; DLCO, diffusion capacity for carbon monoxide; CRP, C-reactive protein; COPD, chronic obstructive pulmonary disease; $\mathrm{RT}$, radiation therapy.

${ }^{a)}$ Radiation Therapy Oncology Group score for acute toxicity. ${ }^{b)}$ Institutional criteria (similar to Common Toxicity Criteria [CTC]), ${ }^{c}$ Southwest Oncology Group score. ${ }^{\text {d) }}$ CTC, ver. 4.0.

radiation pneumonitis was lower in patients with involvedfield irradiation (IFI) than in patients with elective nodal irradiation (ENI) (17\% vs. 29\%, p = 0.044). In addition, IMRT could deliver 25-30\% higher dose within the target and achieve improved critical structure sparing, compared to 3D radiotherapy [34]. Murshed et al. [35] compared IMRT and $3 \mathrm{D}$-conformal radiation therapy (CRT) plans in 41 NSCLC patients and reported that IMRT planning improved target conformity, without significantly sacrificing the homogeneity of the tumor dose. The median absolute reduction in the percentage of lung volume irradiated to $>10$ and $>20$ Gy were $7 \%$ and 10\%, respectively. This corresponded to a decrease of $>2$ Gy in the total lung mean dose and of $10 \%$ in the risk of radiation pneumonitis. Kim [36] reported that of
105 NSCLC patients treated with IMRT, 21 patients (20\%) had abnormal radiological findings, but only seven patients (6.7\%) required treatment for radiation pneumonitis and suggested that IMRT could be a beneficial treatment modality for the reduction of radiation pneumonitis in NSCLC patients.

In conclusion, twenty-five cases (51.0\%) out of 49 cases experienced radiation pneumonitis and 15 cases were grade $\geq 2$ radiation pneumonitis. Among clinical factors, only concurrent rather than sequential chemotherapy was significantly related to grade $\geq 2$ radiation pneumonitis. The dosimetric factors MLD and $V_{30}$ were statistically significant predictors of grade $\geq 2$ radiation pneumonitis. The cutoff values for MLD and $V_{30}$ were 16 Gy and 18\%, respectively. Toxicities related to radiotherapy depend on total radiation dose and treatment field; therefore, $\mathrm{V}_{20}, \mathrm{~V}_{30}$, and MLD should be below 25\%, 18\%, and $16 \mathrm{~Gy}$, respectively. For reducing irradiation of normal tissue, omission of clinically uninvolved lymph-node areas, and more advanced treatment technique, such as IMRT, respiratory gating and image guidance, could be recommended. In addition, radiation protector to prevent radiation pneumonitis should be investigated.

\section{Conflict of Interest}

No potential conflict of interest relevant to this article was reported.

\section{References}

1. Ministry for Health, Welfare and Family Affairs. Annual report of cancer incidence (2007), cancer prevalence (2007) and survival (1993-2007) in Korea. Seoul: Ministry for Health, Welfare and Family Affairs; 2009.

2. Morton RF, Jett JR, McGinnis $W L$, et al. Thoracic radiation therapy alone compared with combined chemoradiotherapy for locally unresectable non-small cell lung cancer: a randomized, phase III trial. Ann Intern Med 1991;115:681-6.

3. Onn A, Vaporciyan AA, Chang JY, Komaki R, Roth JA, Herbst RS. Cancer of the lung. In: Kufe DW, Bast RC, Hait WN, et al. editors. Cancer medicine. 7th ed. London: BC Decker Inc; 2006. p. 1179-224.

4. Furuse K, Fukuoka M, Kawahara M, et al. Phase III study of concurrent versus sequential thoracic radiotherapy in combination with mitomycin, vindesine, and cisplatin in unresectable stage III non-small-cell lung cancer. J Clin Oncol 1999;17:2692-9.

5. Curran WJ, Scott $C B$, Langer $C J$, et al. Long-term benefit is observed in a phase III comparison of sequential vs concurrent chemo-radiation for patients with unresected stage III nsclc: 
RTOG 9410. Proc Am Soc Clin Oncol 2003;22:2499.

6. Emami B, Lyman J, Brown A, et al. Tolerance of normal tissue to therapeutic irradiation. Int J Radiat Oncol Biol Phys 1991;21:109-22.

7. Salinas FV, Winterbauer RH. Radiation pneumonitis: a mimic of infectious pneumonitis. Semin Respir Infect 1995;10:14353.

8. Gross NJ. Pulmonary effects of radiation therapy. Ann Intern Med 1977;86:81-92.

9. Stover DE. Devita VT, Hellman S, Rosenberg SA, editors. Cancer: principles and practice of oncology. 7th ed. Philadelphia: J. B. Lippincott; 2005.

10. Robnett TJ, Machtay M, Vines EF, McKenna MG, Algazy KM, McKenna WG. Factors predicting severe radiation pneumonitis in patients receiving definitive chemoradiation for lung cancer. Int J Radiat Oncol Biol Phys 2000;48:89-94.

11. Yamada M, Kudoh S, Hirata K, Nakajima T, Yoshikawa J. Risk factors of pneumonitis following chemoradiotherapy for lung cancer. Eur J Cancer 1998;34:71-5.

12. Segawa Y, Takigawa N, Kataoka M, Takata I, Fujimoto N, Ueoka $\mathrm{H}$. Risk factors for development of radiation pneumonitis following radiation therapy with or without chemotherapy for lung cancer. Int J Radiat Oncol Biol Phys 1997;39:91-8.

13. Byhardt RW, Scott C, Sause WT, et al. Response, toxicity, failure patterns, and survival in five Radiation Therapy Oncology Group (RTOG) trials of sequential and/or concurrent chemotherapy and radiotherapy for locally advanced nonsmall-cell carcinoma of the lung. Int J Radiat Oncol Biol Phys 1998;42:469-78.

14. Graham MV, Purdy JA, Emami B, et al. Clinical dose-volume histogram analysis for pneumonitis after 3D treatment for non-small cell lung cancer (NSCLC). Int J Radiat Oncol Biol Phys 1999;45:323-9.

15. Hernando ML, Marks LB, Bentel GC, et al. Radiation-induced pulmonary toxicity: a dose-volume histogram analysis in 201 patients with lung cancer. Int J Radiat Oncol Biol Phys 2001:51:650-9

16. Tsujino $K$, Hirota $S$, Endo $M$, et al. Predictive value of dosevolume histogram parameters for predicting radiation pneumonitis after concurrent chemoradiation for lung cancer. Int J Radiat Oncol Biol Phys 2003;55:110-5.

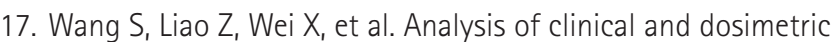
factors associated with treatment-related pneumonitis (TRP) in patients with non-small-cell lung cancer (NSCLC) treated with concurrent chemotherapy and three-dimensional conformal radiotherapy (3D-CRT). Int J Radiat Oncol Biol Phys 2006;66:1399-407.

18. Fay M, Tan A, Fisher R, Mac Manus M, Wirth A, Ball D. Dose-volume histogram analysis as predictor of radiation pneumonitis in primary lung cancer patients treated with radiotherapy. Int J Radiat Oncol Biol Phys 2005;61:1355-63.

19. Schallenkamp JM, Miller RC, Brinkmann DH, Foote T, Garces YI. Incidence of radiation pneumonitis after thoracic irradiation: Dose-volume correlates. Int J Radiat Oncol Biol Phys 2007;67: 410-6.

20. Bradley JD, Hope A, El Naqa I, et al. A nomogram to predict radiation pneumonitis, derived from a combined analysis of RTOG 9311 and institutional data. Int J Radiat Oncol Biol Phys 2007;69:985-92.

21. Tsoutsou PG, Koukourakis MI. Radiation pneumonitis and fibrosis: mechanisms underlying its pathogenesis and implications for future research. Int J Radiat Oncol Biol Phys 2006;66:1281-93.

22. Inoue $A$, Kunitoh $H$, Sekine I, Sumi $M$, Tokuuye $K$, Saijo N. Radiation pneumonitis in lung cancer patients: a retrospective study of risk factors and the long-term prognosis. Int J Radiat Oncol Biol Phys 2001;49:649-55.

23. Rodrigues G, Lock M, D'Souza D, Yu E, Van Dyk J. Prediction of radiation pneumonitis by dose - volume histogram parameters in lung cancer: a systematic review. Radiother Oncol 2004;71:127-38.

24. Roach M 3rd, Gandara DR, Yuo HS, et al. Radiation pneumonitis following combined modality therapy for lung cancer: analysis of prognostic factors. J Clin Oncol 1995;13:2606-12.

25. Oetzel D, Schraube P, Hensley F, Sroka-Perez G, Menke M, Flentje M. Estimation of pneumonitis risk in three-dimensional treatment planning using dose-volume histogram analysis. Int J Radiat Oncol Biol Phys 1995;33:455-60.

26. Seppenwoolde Y, De Jaeger K, Boersma LJ, Belderbos JS, Lebesque JV. Regional differences in lung radiosensitivity after radiotherapy for non-small-cell lung cancer. Int J Radiat Oncol Biol Phys 2004;60:748-58.

27. Yorke ED, Jackson $A$, Rosenzweig KE, Braban L, Leibel SA, Ling CC. Correlation of dosimetric factors and radiation pneumonitis for non-small-cell lung cancer patients in a recently completed dose escalation study. Int J Radiat Oncol Biol Phys 2005;63:672-82.

28. Ramella S, Trodella L, Mineo TC, et al. Adding ipsilateral V20 and $\mathrm{V} 30$ to conventional dosimetric constraints predicts radiation pneumonitis in stage IIIA-B NSCLC treated with combined-modality therapy. Int J Radiat Oncol Biol Phys 2010;76:110-5.

29. Rancati T, Ceresoli GL, Gagliardi G, Schipani S, Cattaneo GM. Factors predicting radiation pneumonitis in lung cancer patients: a retrospective study. Radiother Oncol 2003;67:27583.

30. Antonadou D, Coliarakis N, Synodinou M, et al. Randomized phase III trial of radiation treatment $+/$ - amifostine in patients with advanced-stage lung cancer. Int J Radiat Oncol Biol Phys 2001;51:915-22. 
31. Komaki R, Lee JS, Milas $L$, et al. Effects of amifostine on acute toxicity from concurrent chemotherapy and radiotherapy for inoperable non-small-cell lung cancer: report of a randomized comparative trial. Int J Radiat Oncol Biol Phys 2004;58:136977.

32. Mehta V. Radiation pneumonitis and pulmonary fibrosis in non-small-cell lung cancer: pulmonary function, prediction, and prevention. Int J Radiat Oncol Biol Phys 2005;63:5-24.

33. Yuan $S$, Sun $X_{1}$ Li M, et al. A randomized study of involved-field irradiation versus elective nodal irradiation in combination with concurrent chemotherapy for inoperable stage III nonsmall cell lung cancer. Am J Clin Oncol 2007;30:239-44.
34. Beckmann GK, Kölbl O, Krieger T, Wulf J, Flentje MP. How can we further improve radiotherapy for stage-III non-small-cell lung cancer? Lung Cancer 2004;45(Suppl 2):S125-32.

35. Murshed H, Liu HH, Liao Z, et al. Dose and volume reduction for normal lung using intensity-modulated radiotherapy for advanced-stage non-small-cell lung cancer. Int J Radiat Oncol Biol Phys 2004;58:1258-67.

36. Kim MS. Incidence and prognostic factors of radiation pneumonitisin NSCLC treated with intensity modulated radiation therapy (IMRT). J Korean Soc Ther Radiol Oncol 2008;26:35-44. 